УДК 378.147.227:614.8

DOI 10.37386/2413-4481-2020-3-39-42

\author{
М.М. Иванова \\ Алтайский государственный педагогический университет, г. Барнаул, Россия
}

ОПОРНЫЕ КОНСПЕКТЫ

КАК СРЕДСТВО ПОВЫШЕНИЯ КАЧЕСТВА ЗНАНИЙ СТУДЕНТОВ ПО ДИСЦИПЛИНЕ «БЕЗОПАСНОСТЬ ЖИЗНЕДЕЯТЕЛЬНОСТИ»

\begin{abstract}
В данной статье представлен опыт использования методики опорных конспектов В.Ф. Шаталова при подготовке учителей в системе высшего образования. Описывается педагогический эксперимент, связанный с применением опорных конспектов у студентов первого курса при изучении дисциплины «Безопасность жизнедеятельности».

Ключевые слова: опорный конспект, опорный сигнал, студенты, безопасность жизнедеятельности, качество знаний, будущий специалист, методика, первокурсники, высшее профессиональное образование.
\end{abstract}

M.M. Ivanova

Altai State Pedagogical University, Barnaul, Russia

\title{
STUDENTS' SUPPORTIVE STUDY-NOTES AS A STRATEGY FOR IMPROVING THEIR PROFICIENCY LEVEL IN THE COURSE “LIFE SAFETY”
}

This article presents some best practices of using the methodology of supportive study-notes for students introduced by V.F. Shatalov in teacher-training higher education. The article describes the pedagogical experiment based on supportive study-notes for first-year students in the university course "Life Safety".

Key words: supportive study-notes, supportive signal, students, life safety, proficiency level, would-be professional, methodology, freshmen, higher professional education.

Современный мир требует от человека запоминания большого количества информации во всех сферах жизни. То же касается области профессионального образования. Чтобы стать высококвалифицированным специалистом, необходимо качественное освоение образовательных программ. Особую актуальность это приобретает для студентов первого курса. Студенту необходимо усвоить больший, по сравнению со школой, объем информации, что требует увеличения временных затрат, усилий и терпения. Условия обучения в школах, выпускниками которых является большинство первокурсников, не совпадают с условиями обучения в системе высшего образования. Это обусловливает необходимость адаптации бывшего школьника к новым требованиям, к иной, чем в школе, организации учебного процесса. Первокурснику необходимо проявлять самостоятельность, инициативность и активность в освоении знаний, а это, в свою очередь, требует большей ответственности за свое образование. Кроме того, в период социально-психологической адаптации у студентов первого курса происходит кардинальная смена деятельности и окружения, их внутренние установки претерпевают значительные трансформации. Происходит переориентация ценностей, освоение новых социальных ролей, студенты по-другому начинают воспринимать себя и социальное окружение. Данная проблема ведет к снижению уровня знаний, интереса и продуктивности обучающихся (Г.В. Безюлева, С.В. Васильева, Т.Д. Дубовицкая, Н.Г. Колызаева, И.В. Коровина, С.Т. Посохова и др.). В этой связи возникает необходимость в альтернативных методах обучения для использования в системе современного высшего образования.

Основная задача качественно новой образовательной системы сводится к достижению устойчивого интереса студентов к изучаемому предмету, к самообразованию, начиная с первого курса обучения, а также к привлечению к научным поискам. Студент как будущий специалист должен понимать, каким образом, получив социальные и профессиональные навыки, он сможет применить их в практической деятельности. В настоящее время активно идет модернизация на всех уровнях профессионального образования. Инновационный подход в образовании активи- 
зирует поиск и внедрение усовершенствованных образовательных технологий и методик обучения будущих специалистов, к которым относятся игровые, проектные, информационные, проблемно-модульные технологии, метод кейсов и др. (А.А. Вербицкий, В.И. Загвязинский, И.Я. Лернер, В.Я. Ляудис, А.М. Матюшкин, М.И. Махмутов и др.). В настоящее время преподаватель высшей школы не ограничен в выборе средств, методов и технологий обучения. Рациональное сочетание имеющихся и инновационных подходов смогут помочь педагогу в решении поставленных задач. В связи с обозначенными выше обстоятельствами на основе анализа научно-педагогической и специальной литературы нами была выбрана методика создания опорных конспектов В.Ф. Шаталова для внедрения в образовательный процесс высшей школы.

Виктор Федорович Шаталов - народный учитель СССР, педагог-новатор, почетный доктор Академии педагогических наук Украины, заслуженный учитель Украины, профессор Донецкого института социального образования. В 1956 г. В.Ф. Шаталов организовал экспериментальные классы в школе по своей методике, над которой работал 13 лет. Первый подобный класс из 33 человек изучил полный курс школы на 2 года раньше, показав высокие результаты. В последующем в высшие учебные заведения поступило 100 \% его учеников. В настоящее время 64 ученика Шаталова имеют звания кандидата наук, 15 - доктора наук. В.Ф. Шаталов совершенствовал собственную методику все последующие годы [1-3]. Им подготовлено и опубликовано множество научных трудов по теме исследования, он стал сотрудником научно-исследовательского института педагогики, а также членом Академии педагогических наук СССР. В результате проделанной работы им разработана система обучения с использованием опорных конспектов, основанных на опорных сигналах, т. е. взаимосвязи ключевых слов, условных знаков, рисунков, формул с кратким выводом. Согласно концепции автора, конспект - это форма краткого изложения информации, основанная на опорных сигналах. Конспект способен мгновенно восстанавливать в памяти известную ранее информацию посредством возникающих ассоциаций и творческого мышления. По мнению В.Ф. Шаталова, головной мозг человека лучше воспринимает информацию, которая оригинально зашифрована, поэтому опорные сигналы эффективно помогают в переработке и запоминании большого количества информации [4].

Основными принципами обучающей методики В.Ф. Шаталова являются:
1) обучение на высоком уровне сложности,

2) бесконфликтность,

3) быстрое движение вперед,

4) открытые перспективы,

5) сверхмногократное повторение,

6) ведущая роль теоретических знаний,

7) гласность.

Этапы создания опорных конспектов заключаются в следующем алгоритме:

- внимательное чтение раздела учебника, вычисление основных взаимосвязей;

- краткое изложение главных мыслей в том порядке, в котором они следуют в тексте;

- преобразование данных тезисов в графическую и знаково-символическую форму;

- обособление блоков контурами и графическое отображение связи между ними;

- выделение значимых элементов цветом.

Уникальность данной методики заключается, прежде всего, в том, что в результате ее применения даже ученик с низкой успеваемостью на высоком уровне усваивает учебный материал и успешно использует его на практике через определенный промежуток времени. При помощи опорных конспектов некоторые высококвалифицированные спортсмены успешно совмещали школьную программу с тренировочным процессом. Методика В.Ф. Шаталова в настоящее время используется самостоятельно школьниками, студентами, педагогами в некоторых школах России и Украины. В Китае данная методика принята на государственном уровне, по ней готовят профессиональных военных [3].

При обучении высококвалифицированных специалистов любой сферы профессиональной деятельности, включая учителей физической культуры, тренеров, в образовательную программу включена дисциплина «Безопасность жизнедеятельности» (БЖД), целью которой является формирование знаний, умений и навыков обеспечения безопасности действий в различных ситуациях. Под безопасностью жизнедеятельности как наукой подразумевается система знаний, обеспечивающая безопасность человека в производственной и непроизводственной среде, развитие деятельности по обеспечению безопасности с учетом различного влияния на окружающую среду. Знания и умения в области этой дисциплины являются необходимыми как для повседневной жизни, так и для профессионального становления человека. Уроки физической культуры, спортивные тренировки имеют повышенный уровень травмоопасности, по сравнению с другими уроками. В связи с этим актуальность дисциплины 
БЖД в профессиональной подготовке кадров для сферы физической культуры и спорта (ФКиС) имеет огромное значение. Кроме того, БЖД составляет основу деятельности военно-спортивных и патриотических клубов, раздел «Автономное выживание» данной дисциплины включен в программу обучения спортивному туризму и спортивному ориентированию [5-7].

Компетенции, приобретаемые студентами при освоении дисциплины БЖД, должны быть усвоены в максимально полном объеме. Для этого необходимо применять наиболее эффективные методики обучения и усвоения материала, что и определило использование методики опорных конспектов В.Ф. Шаталова.

С сентября по декабрь 2019 года на базе ФГБОУ ВО «АлтГПУ» в институте физической культуры и спорта на первом курсе был проведен педагогический эксперимент. Целью эксперимента являлось выявление влияния опорных конспектов, составленных по методике В.Ф. Шаталова, на качество знаний и интерес студентов при изучении дисциплины «Безопасность жизнедеятельности».

Объектом исследования являлся учебный процесс студентов института физической культуры и спорта по дисциплине «Безопасность жизнедеятельности».

Предмет исследования - опорные конспекты по методике В.Ф. Шаталова, их влияние на повышение качества знаний студентов ИФКиС.

Гипотеза исследования - создание и применение опорных конспектов по методике В.Ф. Шаталова способствует повышению качества знаний и интереса к изучению дисциплины «Безопасность жизнедеятельности».

Для достижения цели были определены следующие задачи исследования:

1. Изучение литературы по проблеме исследования.

2. Создание системы опорных конспектов по дисциплине «Безопасность жизнедеятельности».

3. Внедрение опорных конспектов по методике В.Ф. Шаталова в учебный процесс по дисциплине «Безопасность жизнедеятельности».

4. Выявление эффективности внедрения опорных конспектов по дисциплине «Безопасность жизнедеятельности» в учебный процесс студентов первого курса ИФКиС.

Методы исследования: анализ научной литературы, педагогическое наблюдение, тестирование, беседа, педагогический эксперимент, методы математической обработки данных.

Выборку составили 60 студентов первого курса ИФКиС $(\mathrm{N}=60)$ : 30 - контрольная группа, 30 экспериментальная группа.
Учебная дисциплина «Безопасность жизнедеятельности» была реализована в рамках 16 часов лекций и 16 часов практических занятий. В учебном процессе, как в экспериментальной, так и в контрольной группе, был задействован один преподаватель.

В контрольной группе использовались традиционные методы обучения. В экспериментальной группе педагог применял методику В.Ф. Шаталова и обучал студентов созданию опорных конспектов. Студенты экспериментальной группы совместно с преподавателем, а далее самостоятельно, при изучении каждой темы разрабатывали свои опорные конспекты, которые использовались на практических занятиях.

Кроме того, было важно отследить динамику интереса студентов к предмету ОБЖ, а также их активность и настроение на учебных занятиях. Для этого мы использовали модифицированную методику «Самочувствие. Активность. Настроение» (САН), с помощью которой выявляли познавательный интерес, активность и настроение на занятиях ОБЖ. Поскольку измерение самочувствия не давало актуальной информации в контексте изучаемой проблемы, данный параметр был заменен на «Интерес». Данную методику мы проводили в середине и конце семестра в контрольной и экспериментальной группах.

Для количественного и качественного анализа, интерпретации результатов экспериментальной работы был применен метод математической статистики « $\mathrm{X}^{2} \mathrm{X}^{2}$ критерий». Данный метод позволяет выявить различия результатов в группах на констатирующем и контрольном этапах эксперимента. Расчет велся по формуле:

$$
\begin{aligned}
& \mathrm{X}^{2}=\frac{1}{\mathrm{~N} 1 . \mathrm{N} 2} \sum \frac{(\mathrm{N} 1 . \mathrm{O} 2 i-\mathrm{N} 2 . \mathrm{O} 1 i) 2}{\mathrm{O} 1 i+\mathrm{O} 2 i} \\
& \frac{1}{\mathrm{~N} 1 . \mathrm{N} 2} \sum \frac{(\mathrm{N} 1 . \mathrm{O} 2 i-\mathrm{N} 2 . \mathrm{O} 1 i) 2}{\mathrm{O} 1 i+\mathrm{O} 2 i}
\end{aligned}
$$

Результаты исследования интереса к дисциплине «Безопасность жизнедеятельности» представлены в таблице 1.

С помощью $\mathrm{X}^{2} \mathrm{X}^{2}$ критерия мы выявили, что интерес в данной группе остался без изменений, статистически значимой разницы не обнаружено $\left(\mathrm{X}^{2} \mathrm{X}^{2}=2,7\right)$. По итогам расчета по методике $\mathrm{X}^{2} \mathrm{X}^{2}$ критерий мы выявили, что в экспериментальной группе изменения произошли. Уровень интереса к изучаемой дисциплине значительно возрос $\left(\mathrm{X}^{2} \mathrm{X}^{2}=12,89\right)$. Было выявлено повышение интереса к изучаемой дисциплине. Данное изменение 
мы связываем с применением опорных конспектов. В контрольной группе статистически значимой разницы не обнаружено.

В конце семестра по завершению изучения дисциплины в двух группах было проведено ито- говое контрольное тестирование по усвоению дисциплины. Согласно принятому в АлтГПу «Положению о балльно-рейтинговой системе», результаты тестирования распределены следующим образом [8] (см. табл. 1).

Таблица 1

Сравнительные результаты исследования интереса к дисциплине «Безопасность жизнедеятельности», чел.

\begin{tabular}{|c|c|c|c|c|}
\hline \multirow{2}{*}{ Уровень интереса } & \multicolumn{2}{|c|}{ Контрольная группа } & \multicolumn{2}{|c|}{ Экспериментальная группа } \\
\cline { 2 - 5 } & До эксперимента & После эксперимента & До эксперимента & После эксперимента \\
\hline Высокий & 17 & 15 & 16 & 25 \\
\hline Средний & 7 & 10 & 8 & 5 \\
\hline Низкий & 6 & 5 & 6 & 0 \\
\hline
\end{tabular}

«Неудовлетворительно» (0-50 баллов);

«Удовлетворительно» (51-69 баллов);

«Хорошо» (70-84);

«Отлично» (85-100).

Результаты итогового тестирования по усвоению итоговой дисциплины представлены в таблице 2 .
С целью определения влияния опорных конспектов на успеваемость мы воспользовались расчетом $\mathrm{X}^{2} \mathrm{X}^{2}$ критерия, по итогам которого было выявлено на статистически достоверном уровне отличие результатов в двух выборках $\left(\mathrm{X}^{2} \mathrm{X}^{2}=11,3\right)$.

Таблица 2

Результаты контрольного тестирования по усвоению дисциплины «Безопасность жизнедеятельности», чел.

\begin{tabular}{|c|c|c|}
\hline Уровень усвоения & Контрольная группа & Экспериментальная группа \\
\hline Отлично & 10 & 6 \\
\hline Хорошо & 14 & 0 \\
\hline Удовлетворительно & 4 & 0 \\
\hline Неудовлетворительно & 2 & 0 \\
\hline
\end{tabular}

Результаты проведенного исследования свидетельствуют, что в экспериментальной группе качество знаний выше, чем в контрольной, что подтверждено методом математической статистики. Также была проведена беседа, в результате которой мы выяснили, что студенты и в дальнейшем намерены использовать опорные конспекты при изучении других дисциплин в процессе профессионального обучения. Студенты оценили компактность, экономичность, логичность, высокую информативность данной методики.
Таким образом, результаты проведенного исследования свидетельствуют об эффективности использования опорных конспектов при профессиональной подготовке студентов института физической культуры и спорта. Цель исследования достигнута, задачи решены, гипотеза подтверждена. Перспективы нашего исследования мы связываем с возможностью использования данных конспектов при изучении других дисциплин в процессе освоения программ высшего профессионального образования.

\section{Библиографический список}

1. Эрганова Н. Е. Методика профессионального обучения: учеб. пособие. Екатеринбург: Изд-во Рос. гос. проф. пед. ун-та, 2004. 150 с.

2. Джуринский А. Н. Сравнительная педагогика: учебник для магистров. Люберцы: Юрайт, 2016. 440 с.

3. Кузнецов В. В. Общая и профессиональная педагогика: учебник и практикум для прикладного бакалавриата. М.: Юрайт, 2019. 156 с.

4. Шаталов В. Ф. Эксперимент продолжается. М.: Педагогика, 1989. 206 с.

5. Калмыкова Н. В., Петряева С. Ф. Опорный конспект как один из способов представления учебной информации // Молодой ученый. 2015. № 11.1. С. 53-58.

6. Леонтьев А. Н. Развитие памяти. Экспериментальное исследование высших психических функций. М.; Л.: Учпедгиз, 1931. 278 с.

7. Крепша Н. В. Безопасность жизнедеятельности: учеб. пособие для иностранных студентов. Томск: Изд-во Томского политех. ун-та, 2014. 198 с.

8. Положение о балльно-рейтинговой системе. URL: https://old.altspu.ru/norm/norm_files/2063-uchebnayadeyatelnost.html (дата обращения: 20.03.2020). 